\title{
A study of olive mill waste water removal by a biosorbent prepared by olive stones
}

\author{
Wafaa Yassine ${ }^{1, *}$, Souad Zyade ${ }^{1}$, Said Akazdam ${ }^{1, *}$, Abdelhafid Essadki ${ }^{1}$, Bouchaib Gourich ${ }^{1}$ and \\ Driss Benmessaoud Left ${ }^{2}$ \\ ${ }^{1}$ Laboratory of Engineering, Processes and Environment (LEPE), High School of Technology, University \\ Hassan II of Casablanca Morocco \\ ${ }^{2}$ Laboratory of Interface Materials Environment, Faculty of Sciences Ain Chock, University Hassan II of \\ Casablanca, Morocco
}

\begin{abstract}
In this work, olive mill wastewater (OMW) such as dyes is very toxic even present as traces in industrial wastewater effluents. It may constitute a potential pollution source of ground waters and hence it has to be eliminated. Various low cost adsorbents have been studied for their applicability in treatment of different types of effluents. In this study, the potential of activated carbon derived from Olive Stones was studied for the removal of OMW. The biosorption of OMW from aqueous solutions by Olive Stones (OLS) as a low-cost, natural and eco-friendly biosorbent was investigated and by $\mathrm{KOH}$ and $\mathrm{H}_{3} \mathrm{PO}_{4}$ treated Olive Stones (AOLS). Biosorption kinetic data were properly fitted with the pseudo-second-order kinetic model. The experimental isotherm data were analyzed using Langmuir, Freundlich isotherm equations. The best fit was obtained by the Langmuir model with a Langmuir maximum monolayer biosorption capacity of $189,83 \mathrm{mg} / \mathrm{g}$ for OMW. The biosorption was exothermic in nature $\left(\Delta \mathrm{H}^{\circ}=-105,54 \mathrm{~kJ} / \mathrm{mol}\right)$. The reaction was accompanied by a decrease in entropy. The Gibbs energy $\left(\Delta \mathrm{G}^{\circ}\right)$ increased when the temperature was increased from 303 to $320{ }^{\circ} \mathrm{K}$ indicating a decrease in feasibility of biosorption at higher temperatures. The results have established good potentiality for the Olive Stones to be used as a sorbent for the removal of olive mill wastewater.
\end{abstract}

Keywords: Adsorption, Olive Stones; eco-friendly biosorbent; Olive Mill Wastewater; Kinetics, Equilibrium; Thermodynamics.

\section{Introduction}

Olive oil production is concentrated mainly in Mediterranean countries: Spain, Italy, Greece, Turkey, Syria, Tunisia and Morocco. The production of these countries accounts $94 \%$ of world production which reached 2.5 million tons in $2001^{1}$. Liquid effluents from olive oil mills have a brown to reddish-brown, cloudy appearance ${ }^{2}$. These effluents have a high saline load and are highly acidic, rich in organic matter and low biodegradable polyphenols ${ }^{3}$. The olive industry, in addition to the main production which is the oil, leaves two byproducts which are the pomace and vegetation water also called vegetable water, these effluents have a little economic value in Morocco. Vegetables, acid discharges and leaking due to their rich organic matter pose serious problems of environmental contamination.

Olive Mill Wastewater containing phenolic compounds are a serious environmental problem, and these waters cannot simply be released into the environment without treatment. Phenol has been categorized as a hazardous material by dint of the damage that can do when it gets in to the body of living beings. Though it is not listed as a carcinogenic substance phenol can make severe damage to the living organs ${ }^{4}$. Literature reveals that the overexposure of phenol affects on the central nervous system. In such situations the results are catastrophic as the damage is irreversible. Phenol is an organic compound commonly used in various industrial applications ${ }^{5}$. It is a raw material used in many industries such as cleaning agent manufacturing, pesticides in agricultural industry and construction of automobiles and appliances. Accordingly, there is a possibility to discharge phenol contaminated water in to the natural water bodies without treatment. This makes an immense devastation to the entire ecosystem. In order to minimize the hazard causes by phenol, the US Environmental Protection Agency (EPA) has limited the permissible discharge level of phenol to less than $1 \mathrm{mg} / \mathrm{L}^{6}$. Extremely high organic loaded aqueous 
waste is seasonally generated from the olive oil extraction process, so called Olive Mill Wastewater (OMW). In Morocco is disposed directly to sewerage system, whereas the solid waste (olive husk) is dumped into lands nearby the olive mills without treatment. This increases the risk of contaminating soil, surface water resources, and groundwater aquifers. The negative environmental impact of OMW is attributed to poor biodegradation and toxicity of polyphenols present in Olive Mill Wastewater. In industry, the wastewater is generated in large volumes. Hence a convenient method to handle such load is required.

The treatment of liquid effluents from olive oil mills is one of the most important environmental problems of the Mediterranean countries. To reduce their negative effects, several purification processes are implemented. Of all the processes tested for the valorisation and treatment of vegetable waters, very few are applied on an industrial scale. Conventional aerobic or anaerobic biologic treatments are very difficult because of the high levels of vegetable water in suspended matter and organic substances such as polyphenols, sugars, organic acids and tannins. With regard to heat treatments, only a few processes using olive cake as energy source have been applied on an industrial scale. On the other hand, several known physicochemical technologies have already proved their worth in the field of the treatment of these effluents. Among these is the adsorption technique which consists of adsorbing phenolic compounds which are responsible for the harmful effect of vegetable water. The lack of appropriate treatment techniques is causing oil mill owners to reject these effluents in the wild without any prior treatment, resulting in a detrimental impact on the environment which results in soil clogging and pollution of surface waters. underground. Various vegetable water treatment processes have been developed: physical, chemical, biological and combined system; the current trend must be aimed at integrating various technologies to treat low cost vegetable water.

The treatment processes for phenolic wastewater can be classified into two basic categories, a) destructive process such as destructive oxidation with ozone, hydrogen peroxide or manganese oxides and b) recuperative processes such as adsorption into porous solids ${ }^{7}$, membrane separation ${ }^{8}$ and solvent extraction ${ }^{9}$. Adsorption has been recognized as an effective process in most of the industrial water and wastewater treatment ${ }^{10}$. At very low concentration (less than $0.1 \mathrm{~mol} / \mathrm{l}$ ) phenol can be digested by biological treatment whereas at higher concentrations (more than 20mg/l) solvent extraction is being used and adsorption can be effective for the treatment of Olive Mill Wastewater (OMW) at intermediate concentrations ${ }^{11}$ which is the case of the present study. In fact, adsorption using activated carbons has been shown to be one of the most efficient procedures in the elimination of phenolic compounds from wastewater. However, activated carbons are expensive materials which require complex activation processes, and it is therefore mandatory, from an economic point of view, to regenerate them for reuse ${ }^{12}$. Taking these criteria into consideration, the search for a low coast and easily available adsorbent has led many investigators to search more economic and efficient techniques using natural and vegetal adsorbents. However, by far the most frequently used technology is adsorption by a solid phase. Several different adsorbent solids such as activated carbon ${ }^{13}$ silica ${ }^{14}$, glass powder ${ }^{15}$, polymeric resins $^{16}$, fly ash ${ }^{17}$, peat ${ }^{18}$, kaolinite ${ }^{19}$ and zeolites ${ }^{20}$ have all been proposed to remove phenolic pollutants from wastewater. The challenge is to find alternative adsorbents of comparable efficiency but at a practically no cost. The use of agricultural olive stone for biosorption seems to be very promising ${ }^{21}$. The possibility to use such materials as adsorbents, without any complex and expensive pre-treatments makes them an interesting alternative to the use of activated carbons. Further advantages are that they are readily available and do not need regeneration. In particular, olive stone product from the olive mill industry and is very abundant. This requires the value of an added value that can cover the processing costs. Therefore, treatment of these vegetable waters by adsorption seems to be the best technique used because of its simplicity. The present work aims to find a material with a large retention capacity, very available and inexpensive.

The objective of the present research study is the test of adsorption in removing Olive Mill Wastewater (OMW) in aqueous solution by adsorption onto treated olive stone as adsorbent. The influence of several parameters, such as temperature, agitation speed, and initial concentration of phenol and contact time, on the adsorption process was also investigated. The biosorption kinetic data of the biomass was tested by pseudo-first-order, pseudosecond-order kinetic and Elovich models. The equilibrium data were analyzed using Langmuir, Freundlich and Temkin and isotherm models. The thermodynamics of the biosorption was also evaluated.

\section{Material and methods}

\section{Preparation of the biosorbent: Olive Stones}

Starting material Olive stones was provided by a factory from Essaouira (Morocco), is very abundant agricultural by-product, and could be a very adequate raw material to obtain good adsorbent. activated carbon prepared chemically from olive stones proved to be an excellent decontaminant of polluted water with heavy metals and organic compounds like phenols. The preparation of the adsorbent was as followed, olive mill waste was washed several times 
with distilled water at $105 \mathrm{c}$ overnight, crushed, sieved. The resulting material was treatment $\mathrm{H}_{3} \mathrm{PO} 4$ in the adsorption process. FTIR analysis was applied to determine the surface functional groups, using FTIR spectrophotometer (SCO TECH SP-FTIR-1). The FTIR spectral analysis were recorded from 4000 to $400 \mathrm{~cm}-1$ and the samples were prepared as $\mathrm{KBr}$ pellets under high pressure and $\mathrm{pH}$ de point zéro charge of $\mathrm{KOH}$ and $\mathrm{H} 3 \mathrm{PO} 4$ treated Olive Stones (AOLS) were determined ${ }^{22}$.

The olive pomace washed with tap water several times to remove dust and impurities, are dried in the oven at $100^{\circ} \mathrm{C}$ for $24 \mathrm{hr}$ in a mortar and weighed in $100 \mathrm{~g}$ a flask filled with $500 \mathrm{ml}$ of activating agent $\left(\mathrm{H}_{3} \mathrm{PO}_{4}, \mathrm{KOH}\right)$. The mixture is stirred for a period of one hour at a temperature of $60^{\circ} \mathrm{C}$ using a heater balloon. Then the pomace is filtered and put in the oven until complete evaporation. The dry matter is recovered and crushed and the product sieved by sieves of different pore diameters $(0.5,1$ and $1.5 \mathrm{~mm})^{23}$.

\section{Adsorbate Preparation; Separation of Olives mill wastewater}

The olive mill wastewater was taken from a traditional oil mill in Essaouira, during the 2017 2018 olive-growing season. No chemical additives are used during the production of olive oil. After the storage of the samples, the oily and aqueous phases of OMW can be separated either naturally or by centrifugation ${ }^{24}$. Even if they have the same performance, but the slow and the area requirement may limit the first one. The centrifugation allowed us to accelerate the separation of oil and water phase. This separation technique is performed by filling 4 test tubes with $0.250 \mathrm{dm}^{3}$ of OMW solution, they are then centrifuged at a speed of $4000 \mathrm{rpm}$ during 30 minutes using a centrifuger. The oil, having a lower density than water, will be found above the water in the centrifuger. In order to finally isolate the oil, it will be collected using an automatic adjustable pipette. Oil percentage was determined using weight difference $^{25}$.

\section{Adsorption Isotherms}

The batch adsorption experiments were conducted in a set of $250 \mathrm{ml}$ Erlenmeyer flask containing adsorbent and $200 \mathrm{ml}$ of OMW solution at various initial concentrations. The flasks were agitated in an isothermal water-bath shaker at $200 \mathrm{rpm}$ and solution temperature was varied in the range $\left(20-50^{\circ} \mathrm{C}\right)$ and all mixtures were studied until the equilibrium is reached. The filtration of the samples was carried out using disposable syringe filters with a pore size 0.45 $\mu \mathrm{m}$, that were shown first to exhibit no interaction with the phenol during the sampling and to separate the solid phase from the liquid phase, the equilibrium concentrations of phenol in the solution. The $\mathrm{pH}$ of solutions was adjusted with $1 \mathrm{~N} \mathrm{HCl}$ or $1 \mathrm{~N} \mathrm{NaOH}$ solutions ${ }^{26}$.

\section{Adsorption kinetics}

Adsorption kinetics were carried out to establish the influence of several parameters (contact time, temperature, initial concentration of phenol) using a mechanic stirrer. In the biosorption experiments, The Olive Stones was tested for the adsorption of phenol from aqueous solutions at room temperature using the batch reactor technique. Adsorption kinetic experiments were performed by contacting 3L of OMW solution at different initial concentrations ranging from 20 to $100 \mathrm{mg} / \mathrm{L}$ with $3 \mathrm{~g}$ of Olive Stones in reactor at room temperature. At fixed time intervals, the samples were taken from the solution and were separated from the sorbent through a filter and the residual concentration was determined. agitation speed (50-250rpm) and temperature (20 $47^{\circ} \mathrm{C}$ ) values. $\mathrm{PH}$ was measured using a combination $\mathrm{pH}$ associated with $\mathrm{pH}$-meter calibrated beforehand. The respective affects of agitation speed, $\mathrm{pH}$, temperature $(\mathrm{T})$ and adsorbent $\operatorname{mass}\left(m_{0}\right)$.

\section{Adsorption Experiments}

The process of the Olive Mill Wastewater (OMW) adsorption on the Olive Stones necessarily generates a distribution of the adsorbate between the solid and liquid phases as a function of operating conditions. Adsorption experiments were carried out by introducing a quantity of the adsorbent in $1 \mathrm{~L}$ of OMWW solution at initial dilution and at the desired temperature emaintained with a thermostated bath. The mixture was stirred on an electromagnetic stirrer at a constant speed (400 rpm). The controlled parameters are: temperature and adsorbent diameter. Samples of the solution were withdrawn at various time intervals and centrifuged at $2000 \mathrm{rpm}$ for one minute. The removal percentage $(\% \mathrm{R})$ of OMWW is calculated as follows ${ }^{27}$ :

$$
\% \mathrm{R}=\frac{\left(\mathrm{C}_{\mathrm{i}}-\mathrm{C}_{\mathrm{e}}\right)}{\mathrm{C}_{\mathrm{i}}} .100
$$

$\mathrm{Ci}(\mathrm{mg} / \mathrm{l})$ is the initial concentration of OMWW, $\mathrm{Ce}(\mathrm{mg} / \mathrm{L})$ is the dye concentration at equilibrium.

Adsorption capacity is given by the following formula $^{28}$ :

$$
\mathrm{q}_{\mathrm{t}}=\frac{\left(\mathrm{C}_{\mathrm{i}}-\mathrm{C}_{\mathrm{e}}\right)}{\mathrm{C}_{\mathrm{i}}} .100
$$

$\mathrm{q}_{\mathrm{t}}(\mathrm{mg} / \mathrm{g})$ is the amount adsorbed at time $\mathrm{t}(\mathrm{min})$, $\mathrm{Ct}(\mathrm{mg} / \mathrm{L})$ is the dye concentration at time $\mathrm{t}$; $\mathrm{V}(\mathrm{L})$ is the volume of dye solution and $\mathrm{m}(\mathrm{g})$ is the mass of theadsorbent used. The analysis of the instantaneous concentration $C_{t}$ in the filtered liquid phase was carried out using a double beam UV-visible absorption spectrophotometer. The linearity of BeerLambert law was checked for concentration ranging 
from 1 to $48 \mathrm{mg} / \mathrm{L}$ with a correlation coefficient $\mathrm{R}^{2}=0.9997$.

\section{Isotherm Modeling}

The study of adsorption isotherm is necessary in order to understand the adsorption mechanism ${ }^{29}$. In order to investigate the effect of temperature on the equilibrium capacity of Olive Stones adsorbent for the removal of phenol from aqueous solution, the equilibrium of adsorption data was analyzed using Langmuir, Freundlich, and Temkin isotherms models. Linear regression is frequently used to determine the best-fitting isotherm, and the applicability of isotherm equations is compared by judging the correlation coefficients.

\section{Langmuir isotherm}

Langmuir theory ${ }^{30}$ assumes:

- Adsorbent has a limited adsorption capacity $\left(\mathrm{q}_{\max }\right)$

- Adsorbate forms a monolayer on the adsorbent surface

- Active sites are identical

- Absence of interaction between the adsorbed molecules.

Langmuir isotherm is given by the following equation:

$\mathrm{q}_{\mathrm{e}}=\frac{\mathrm{q}_{\max } \mathrm{K}_{\mathrm{L}} \mathrm{C}_{\mathrm{e}}}{1+K_{L} \mathrm{C}_{\mathrm{e}}}$

$\mathrm{C}_{\mathrm{e}}(\mathrm{mg} / \mathrm{L})$ is the concentration of the adsorbate in solution at equilibrium, $\mathrm{q}_{\mathrm{e}}(\mathrm{mg} / \mathrm{g})$ is the adsorbed amount at equilibrium, $\mathrm{q}_{\max }(\mathrm{mg} / \mathrm{g})$ is the maximum adsorption capacity, $\mathrm{K}_{\mathrm{L}}(\mathrm{L} / \mathrm{mg})$ is the Langmuir constant. The linear form of Langmuir isotherm model can be written as followed:

$$
\frac{\mathrm{C}_{\mathrm{e}}}{\mathrm{q}_{\mathrm{e}}}=\frac{\mathrm{C}_{\mathrm{e}}}{\mathrm{q}_{\max }}+\frac{1}{\mathrm{~K}_{\mathrm{L}} \mathrm{q}_{\max }}
$$

The essential characteristic of the Langmuir isotherm can be expressed by the dimensionless constant called equilibrium parameter, $\mathrm{R}_{\mathrm{L}}$, defined by ${ }^{31}$ :

$$
\mathrm{R}_{\mathrm{L}}=\frac{1}{1+\mathrm{K}_{\mathrm{L}} \mathrm{C}_{0}}
$$

where $\mathrm{K}_{\mathrm{L}}$ is the Langmuir constant and $\mathrm{C}_{0}$ is the initial dye concentration. The separation factor $\mathrm{R}_{\mathrm{L}}$ values indicate the type of isotherm to be irreversible $\left(R_{L}=0\right)$, favorable $\left(0<R_{L}<1\right)$, linear $\left(R_{L}\right.$ $=1$ ) or unfavorable $\left(R_{L}>1\right)$.

\section{Freundlich isotherm}

Freundlich model ${ }^{32}$, is applied in the case of multilayer adsorption and describes the equilibrium on heterogeneous surfaces. However, this model assumes the existence of interactions between adsorbed molecules. Freundlich isotherm model can be defined by the following equation:

$$
\mathrm{q}_{\mathrm{e}}=\mathrm{K}_{\mathrm{F}} \mathrm{C}_{\mathrm{e}}^{1 / n}
$$

$\mathrm{qe}(\mathrm{mg} / \mathrm{g})$ is the adsorbed amount at equilibrium, $\mathrm{Ce}$ $(\mathrm{mg} / \mathrm{L})$ is the concentration of the adsorbate in the solution at equilibrium, $\mathrm{kF}$ is the Freundlich constant, $\mathrm{n}$ is the adsorption intensity. Its linear form is given by the following equation:

$\ln \left(\mathrm{q}_{\mathrm{e}}\right)=\ln \left(\mathrm{K}_{\mathrm{F}}\right)+\frac{\ln \left(\mathrm{C}_{\mathrm{e}}\right)}{n}$

\section{Temkin isotherm}

Temkin's model is based on the hypothesis that the heat of adsorption due to interactions with the adsorbate decreases linearly with the recovery rate, whiting liquid phase adsorption ${ }^{33}$. This is an application of the Gibbs relation to the adsorbents, whose surface is considered homogeneous energy.

Temkin equation and its linear form can be given by the following expression:

$$
\begin{aligned}
\mathrm{q}_{\mathrm{e}} & =\mathrm{B} \ln \left(\mathrm{k}_{1} \mathrm{C}_{\mathrm{e}}\right)=\mathrm{B} \ln \left(\mathrm{k}_{1}\right)+B \ln \left(C_{e}\right) \\
\mathrm{B} & =\mathrm{q}_{\max } \frac{R T}{\Delta Q}
\end{aligned}
$$

qe $(\mathrm{mg} / \mathrm{g})$ is the adsorbed amount at equilibrium, qmax $(\mathrm{mg} / \mathrm{g})$ is the maximum amount adsorbed, $\mathrm{T}$ $(\mathrm{K})$ is the absolute temperature, $\Delta \mathrm{Q}(\mathrm{J} / \mathrm{mol})$ is the variation in adsorption energy $k_{l}(\mathrm{~L} / \mathrm{mg})$ is the Temkin constant and $\mathrm{R}$ is the universal gas constant $8.314\left(\mathrm{~J} / \mathrm{mol}^{\circ} \mathrm{K}\right)$. The adsorption data were analyzed according to the linear form of the Temkin isotherm.

\section{Dubinin-Radushkevich $(D-R)$ isotherm}

Another equation used in the analysis of isotherms was proposed by Dubinin-Radushkevich. D-R model

was applied to estimate the porosity apparent free energy and the characteristic of adsorption. The D-R isotherm is not assuming a homogeneous surface or constant sorption potential but its common and linear forms can be ${ }^{34}$ :

$$
\begin{aligned}
& \mathrm{q}_{\mathrm{e}}=\mathrm{q}_{\max } \exp \left(-K \varepsilon^{2}\right) \\
& \mathrm{E}=\frac{1}{\sqrt{2 \mathrm{~K}}}
\end{aligned}
$$

Where $\mathrm{K}$ is a constant related to the adsorption energy, $\mathrm{q}_{\max }$ the theoretical saturation capacity, $\varepsilon$ is the Polanyi potential. $\varepsilon$ can be calculated from (10):

$$
\varepsilon=R T \cdot \ln \left(1+\frac{1}{C_{e}}\right)
$$

The plot's slope of $\ln \left(\mathrm{q}_{\mathrm{e}}\right)$ versus $\varepsilon^{2}$ gives the constant $\mathrm{K}(\mathrm{mol} /(\mathrm{kJ}))$ and the intercept yields to adsorption

capacity, $\mathrm{q}_{\max }(\mathrm{mg} / \mathrm{g})$. $\mathrm{K}$ gives the mean free energy of adsorption (E) per molecule of the sorbate OMW when it is transferred to the surface of the solid 
AOLS from infinity in the solution and can be computed using ${ }^{35}$ :

$$
\ln \left(\mathrm{q}_{\mathrm{e}}\right)=\ln \left(\mathrm{q}_{\max }\right)-K \varepsilon^{2}
$$

The magnitude of $\mathrm{E}$ is useful for estimating the type of adsorption process. Adsorption type can be explained by chemical adsorption if the magnitude of $\mathrm{E}$ is $8-16 \mathrm{~kJ} / \mathrm{mol}$. It's accepted that when the adsorption energy is lower than $8 \mathrm{~kJ} / \mathrm{mol}$, the type of adsorption can be defined as physical adsorption ${ }^{\mathbf{3 6}}$.

\section{Kinetic Models}

There are several kinetic equations available for analyzing experimental sorption. The studies of adsorption equilibrium are important in determining the effectiveness of adsorption; however, it is also necessary to identify the types of adsorption mechanism in a given system. The most famous experimental models obtained in the present work was tested with Pseudo-first, Pseudo-second, intraparticle diffusion, Elovich and Bangham's models to predict the adsorption kinetic of OMWW onto OLS or AOLS and the kinetic data were analyzed based on the regression coefficient $\left(\mathrm{R}^{2}\right)$ and the amount of dye adsorbed per unit weight of the adsorbent.

\section{Pseudo-First-Order Model}

The adsorption kinetic data were described by the Lagergren pseudo-first-order model, which is the earliest known equation describing the adsorption rate based on the solid capacity. The Lagergren equation is generally expresses as follows:

$$
\frac{\mathrm{dq}_{\mathrm{t}}}{\mathrm{dt}}=\mathrm{k}_{1}\left(\mathrm{q}_{\mathrm{e}}-q_{t}\right)
$$

Where $\mathrm{q}_{\mathrm{e}}$ and $\mathrm{q}_{\mathrm{t}}$ are the adsorption capacity at equilibrium and at time $\mathrm{t}$ respectively $(\mathrm{mg} / \mathrm{g}), \mathrm{k}_{1}$ is the rate constant of pseudo-first order adsorption (min1). After integrating and applying the initial conditions (at $\mathrm{t}=0, \mathrm{qt}=0$ and $\mathrm{t}=\mathrm{te}$, $\mathrm{qt}=\mathrm{qe}$ ), the equation takes the form ${ }^{37}$ :

$$
\ln \left(\mathrm{q}_{\mathrm{e}}-\mathrm{q}_{\mathrm{t}}\right)=\ln \left(\mathrm{q}_{\mathrm{e}}\right)-k_{1} t
$$

\section{Pseudo-Second-Order Model}

Adsorption data were also analyzed according to the kinetic model of the pseudo-second-order ${ }^{38}$, which is generally given as in:

$$
\frac{\mathrm{dq}_{\mathrm{t}}}{\mathrm{dt}}=\mathrm{k}_{2}\left(\mathrm{q}_{\mathrm{e}}-q_{t}\right)^{2}
$$

Where $\mathrm{q}_{\mathrm{e}}$ and $\mathrm{q}_{\mathrm{t}}$ are the amounts of AO7 adsorbed $(\mathrm{mg} / \mathrm{g})$ at equilibrium and at time $\mathrm{t}$ ( $\mathrm{min})$, respectively and $\mathrm{k}_{2}(\mathrm{~g} / \mathrm{mg}$. $\mathrm{min})$ is the corresponding rate constants of pseudo-second order adsorption. After integrating and applying the conditions (at $\mathrm{t}=0$, $\mathrm{qt}=0$ and $\mathrm{t}=\mathrm{te}$, $\mathrm{qt}=\mathrm{qe}$ ), the equation takes the linear form:

$$
\frac{\mathrm{t}}{\mathrm{q}_{\mathrm{t}}}=\frac{1}{\left(k_{2} q_{e}^{2}\right)}+\frac{t}{q_{e}}
$$

\section{Elovich Model}

In reactions involving chemisorption of adsorbate on a solid surface without desorption of products, adsorption rate decreases with time due to an increased surface coverage. One of the most useful models for describing chemisorption is the Elovich model. The Elovich model equation is generally expressed as ${ }^{39}$ :

$$
\frac{\mathrm{dq}_{\mathrm{t}}}{\mathrm{dt}}=\alpha \exp \left(-\beta q_{t}\right)
$$

Where $\alpha$ represents the initial adsorption rate ( $\mathrm{mg} / \mathrm{g} \cdot \mathrm{min})$ and $\beta$ is the desorption constant $(\mathrm{g} / \mathrm{mg})$. After integrating for the similar boundary conditions, the following equation can be obtained as:

$\mathrm{q}_{\mathrm{t}}=\frac{1}{\beta} \ln (\alpha \beta)+\frac{1}{\beta} \ln (t)$

The parameters $\alpha$ and $\beta$ can be computed from the slope and intercept of the linear plot of $q_{t}$ versus $\ln$ (t).

\section{Intraparticle diffusion Model}

Adsorption is a multi-step process involving transport of the adsorbate (dye) molecules from the aqueous phase to the surface of the solid particles then followed by diffusion of the solute molecules into the pore interiors. If the experiment is a batch system with rapid stirring, there is a possibility that the transport of sorbate from solution into pores of the adsorbent is the rate-controlling step. Since the OMW is probably transported from its aqueous solution to the OLS or AOLS by intraparticle diffusion, so the intraparticle diffusion is another kinetic model developed by Weber and Morris should be used to study the rate-limiting step for OMW onto OLS or AOLS. The intra-particle diffusion is commonly expressed by ${ }^{40}$ :

$\mathrm{q}_{\mathrm{t}}=\mathrm{k}_{\mathrm{diff}}(t)^{0.5}+c$

Where $\mathrm{C}(\mathrm{mg} / \mathrm{g})$ is the intercept and $\mathrm{K}_{\text {dif }}$ $\left(\mathrm{mg} / \mathrm{gmin}^{1 / 2}\right)$ is the intraparticle diffusion rate constant. The values of the amount of dye adsorbed $\mathrm{q}_{\mathrm{t}}$ were found to give two lines part with values of the square root of time $t^{1 / 2}$.

\section{Bangham's Model}

It is generally expressed as ${ }^{41}$ :

$$
\log \left(\frac{c_{0}}{\left.c_{0}-q_{t} m\right)}\right)=\log \left(\frac{k_{0} m}{2.303 V}\right)+\alpha \log (t)
$$

Where $\mathrm{C}_{0}$ is the initial concentration of the adsorbate in solution $(\mathrm{mg} / \mathrm{L}), \mathrm{V}$ the volume of the solution (1), $\mathrm{m}$ the weight of adsorbent used per liter of solution 
$(\mathrm{g} / \mathrm{L}), \mathrm{q}_{\mathrm{t}}(\mathrm{mg} / \mathrm{g})$ the amount of adsorbate retained at time $\mathrm{t}, \alpha<1$ and $\mathrm{k}_{0}$ are constants determined from the plot of $\log \left[\mathrm{C}_{0} / \mathrm{C}_{0}-\mathrm{mq}_{\mathrm{t}}\right]$ versus $\log (\mathrm{t})$.

\section{Thermodynamic study}

To investigate the adsorption processes, thermodynamic parameters such as $\Delta \mathrm{S}^{\circ}, \Delta \mathrm{H}^{\circ}$ and $\Delta \mathrm{G}^{\circ}$ are calculated for the system OMW/OLS or OMW/AOLS at different temperatures. The evaluation of these parameters is estimated using the following relations (20-21) from the plot of $\ln \left(\mathrm{K}_{\mathrm{L}}\right)$ versus $1 / \mathrm{T}$.

$$
\Delta \mathrm{G}=-\mathrm{RT} \ln \left(\mathrm{k}_{\mathrm{L}}\right)
$$

$\ln K_{L}=\frac{\Delta \mathrm{G}^{\circ}}{\mathrm{RT}}=-\frac{\Delta H^{\circ}}{\mathrm{RT}}+\frac{\Delta S^{\circ}}{R}$

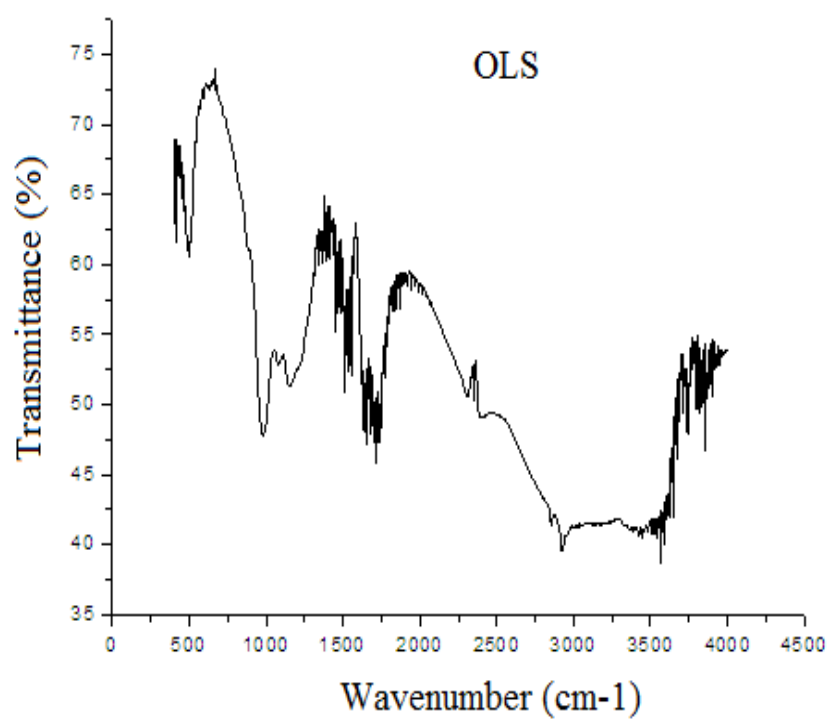

Where $\mathrm{T}\left({ }^{\circ} \mathrm{K}\right)$ is the absolute temperature, $\mathrm{R}$ $(8.314 \mathrm{~J} / \mathrm{mol} . \mathrm{K})$ is the universal gas constant and $\mathrm{K}_{\mathrm{L}}(\mathrm{L} / \mathrm{mg})$ is the constant of Langmuir ${ }^{42}$.

The activation energy of adsorption $E_{a}$ must be determined;

The second order rate constant $\left(\mathrm{k}_{2}\right)$ is expressed as a function of temperature by the Arrhenius equation. The linear form between $\mathrm{k}_{2}$ and temperature can be applied to calculate the activation energy $\left(\mathrm{E}_{\mathrm{a}}\right)$ of the adsorption using (22):

$$
\ln \left(k_{2}\right)=\ln \left(k_{0}\right)-\frac{E_{a}}{R T}
$$

Where $E_{a}$ is the activation energy of sorption $(\mathrm{kJ} / \mathrm{mol}), \mathrm{k}_{0}$ is the temperature-independent factor (g/mg.min), $\mathrm{R}$ is the gas constant $(8.314 \mathrm{~J} / \mathrm{mol} . \mathrm{K})$ and $\mathrm{T}$ is the solution temperature $\left({ }^{\circ} \mathrm{K}\right)$. The physisorption processes usually have activation energies in the range of 5-40 kJ/mol, while higher activation energies (40-800 $\mathrm{kJ} / \mathrm{mol})$ suggest chemisorption $^{43}$.

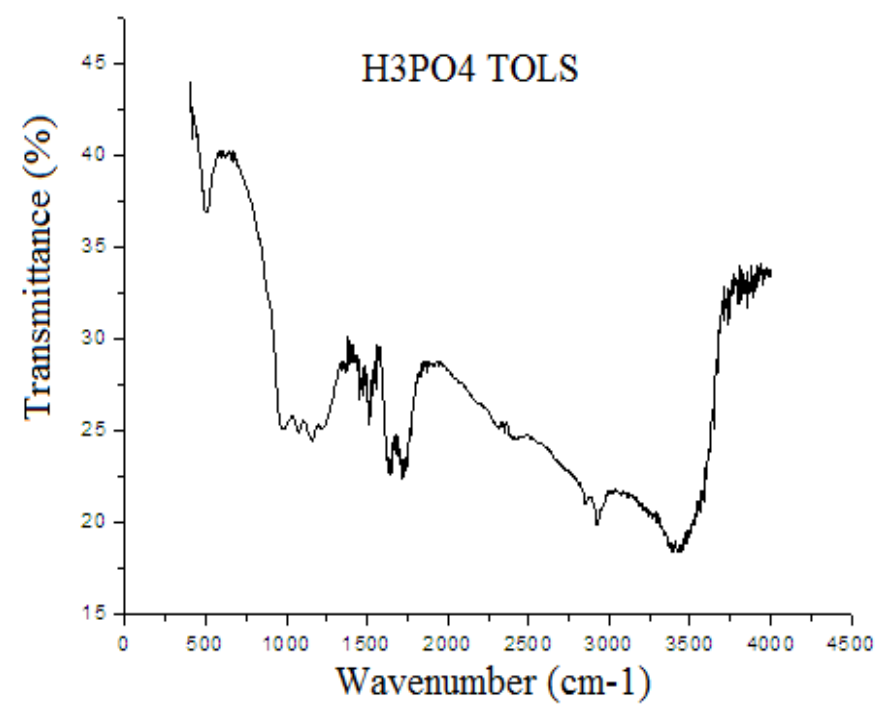

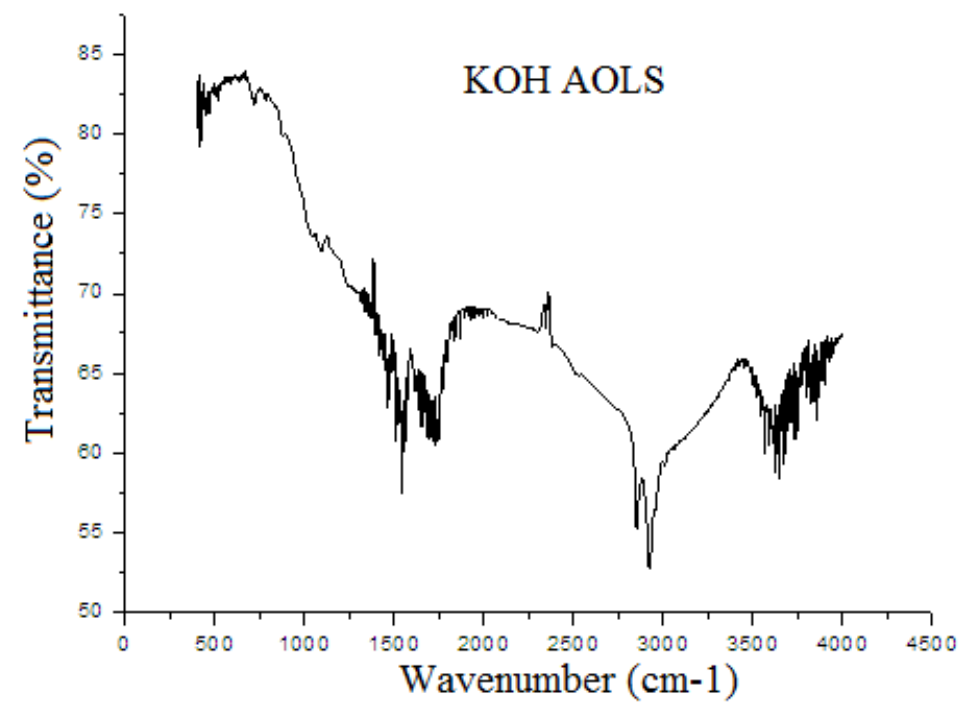

Figure 1. FT-IR spectra of Olive Stones, $\mathrm{KOH}$ and $\mathrm{H}_{3} \mathrm{PO}_{4}$ treated Olive Stones (AOLS) 


\section{Results and Discussion}

\section{FTIR Analysis}

The FT-IR spectra of Olive Stones in the range of $400-4000 \mathrm{~cm}^{-1}$ were taken to obtain information on the nature of functional groups at the surface of the biosorbent. The spectra presented in Fig.1 shows broad, strong and superimposed bands around 3600$3200 \mathrm{~cm}-1$ which may be due to the overlapping of $\mathrm{O}-\mathrm{H}$ and $\mathrm{N}-\mathrm{H}$ stretching vibration. The band at 2921 $\mathrm{cm}-1$ and the band at $2850 \mathrm{~cm}-1$ are due to asymmetric stretching vibration of $\mathrm{CH} 2$ and the symmetric stretching vibration of $-\mathrm{CH} 3$, respectively, of aliphatic acids ${ }^{44}$. The peaks observed between 1730 and $1710 \mathrm{~cm}-1$, are indicative of stretching vibration of $\mathrm{C}-\mathrm{O}$ bonds due to non-ionic carboxyl groups $(-\mathrm{COOH},-\mathrm{COOCH} 3)$ and may be assigned to hydrogen bonding between carboxylic acids or their esters. The stretching vibration band at 1650 $\mathrm{cm}^{-1}$ is due to asymmetric stretching of the carboxylic COO- double bond of deprotonated carboxylate functional groups ${ }^{45}$. A $1432 \mathrm{~cm}-1$ is of phenolic -OH stretching. The peaks observed at 1370 $\mathrm{cm}^{-1}$, which reflect stretching vibrations of symmetrical or asymmetrical ionic carboxylic groups $(-\mathrm{COOH})$ of pectin. The band at $1035 \mathrm{~cm}-1$ band could be due to the vibration of $-\mathrm{C}-\mathrm{O}-\mathrm{C}$ and $-\mathrm{OH}$ of polysaccharides. The peaks at 1254.6 and 1033.5 $\mathrm{cm}^{-1}$ are due to the $\mathrm{C}-\mathrm{O}$ stretching vibration of aldehydes and lactones or carboxyl groups. The band

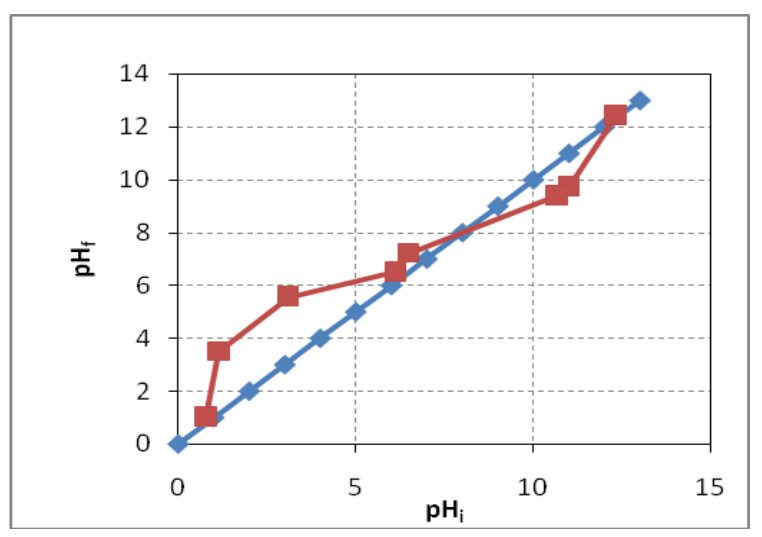

Figure 2. $\mathrm{pH}_{\mathrm{pzc}}$ values for OLS treated by $\mathrm{KOH}$ and $\mathrm{pH}_{\mathrm{pzc}}$ values for OLS treated by $\mathrm{H}_{3} \mathrm{PO}_{4}$

\section{Kinetics adsorption}

The effect of temperature, was carried out in the range of 20 and $47^{\circ} \mathrm{C}$ at constant $\mathrm{pH}$ of 7 by adding $3 \mathrm{~g}$ of $\mathrm{KOH}$ and $\mathrm{H}_{3} \mathrm{PO}_{4}$ treated olive Stones added in each 3 liters of OMW solution and the diameter of adsorbent was carried out in $1.5 \mathrm{~mm}$. The experimental results showed that the adsorbed quantity decrease when temperature increases for the system for the two systems OMW- AOLS $\left(\mathrm{H}_{3} \mathrm{PO}_{4}\right)$ and OMW-AOLS (KOH) (Figure 3). This variation of the temperature generates an increase in the initial rate of adsorption. The results obtained are shown in Fig.3 and indicate that the uptake rate of OMW adsorbed per gram of Olive Stones increase at $1324 \mathrm{~cm}-1$ assigned to $\mathrm{C}-\mathrm{N}$ groups on the biomass surface. The absorption peaks around 1155 and $1070 \mathrm{~cm}-1$ are indicative of $\mathrm{P}=\mathrm{O}$ and $\mathrm{P}-\mathrm{OH}$ stretching vibrations. The S-O stretching was identified at $952 \mathrm{~cm}-1$. Peaks in the region of wavenumbers lower than $800 \mathrm{~cm}^{-1}$ could be attributed to $\mathrm{N}$-containing bioligands. This results indicate that the Olive Stones contain a variety of functional groups such as carboxyl, hydroxyl, sulfate, phosphate, aldehydes, and other charged groups, suggesting that this biomaterial can be considered as an alternative for Olive Mill Wastewater (OMW) removal. The IR analysis spectra obtained on the various adsorbents show the presence of different vibration bands corresponding to hydroxyl groups $\mathrm{O}-\mathrm{H}, \mathrm{C}-\mathrm{N}, \mathrm{C}=\mathrm{O}, \mathrm{C}-\mathrm{H},-\mathrm{COOH}$, $\mathrm{N}-\mathrm{H}$...

\section{pH point zero charge of the biosorbent}

$\mathrm{pH}$ de point zéro charge pHpzc is one of adsorbent characteristics. It was estimated by introducing $0.5 \mathrm{~g}$ of OLS in $50 \mathrm{~mL}$ of distilled water at initial $\mathrm{pH}$ values of $3,4,6,8$ and 10 adjusted by adding required amounts of $\mathrm{NaOH}(0.1 \mathrm{~N})$ or $\mathrm{HCl}$ $(0.1 \mathrm{~N})$. The mixture was stirred for 24 hours at room temperature, and the final $\mathrm{pH}$ was measured. The (Fig.2) representing the variation of the final $\mathrm{pH}$ with the initial $\mathrm{pH}$ gives a pHpzc equal to 8 for AOLS $(\mathrm{KOH})$ and 1 for AOLS $\left(\mathrm{H}_{3} \mathrm{PO}_{4}\right)$.

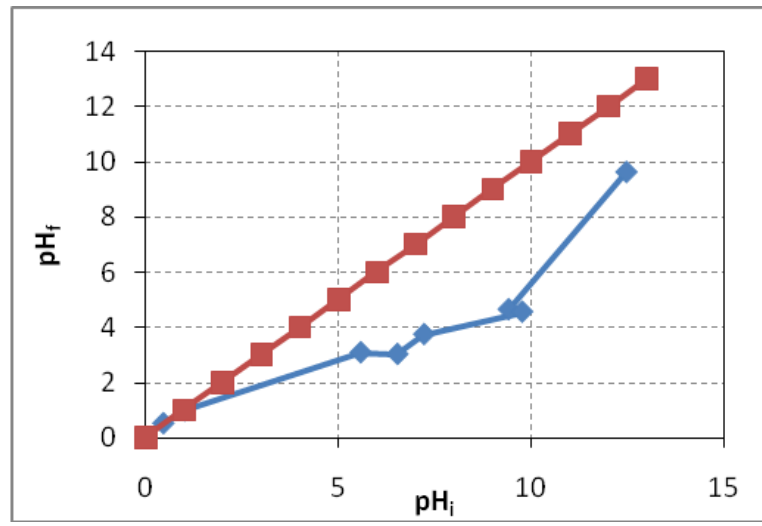
intersection between the first bisectrix and the curve

gradually as the increase in time of OMW at the beginning and, thereafter, the adsorption of OMW reached equilibrium at $170 \mathrm{~min}$. We can say that the equilibrium time is independent of the temperature and the amount adsorbed at equilibrium increases with particle size of adsorbent and decreases with temperature. To determine the effect of temperature on the adsorption of the OMW, experiments were conducted at 20,30 and $47^{\circ} \mathrm{C}$. The equilibrium adsorption increases from 4 to $13 \mathrm{mg} / \mathrm{g}$, with decrease in the temperature of biosorption of OMW from 47 to $20^{\circ} \mathrm{C}$ for the system OMW- AOLS $(\mathrm{KOH})$ and from 10 to $14 \mathrm{mg} / \mathrm{g}$, with decrease in the temperature of biosorption of OMW from 47 to 20

${ }^{\circ} \mathrm{C}$ for the system OMW- AOLS $\left(\mathrm{H}_{3} \mathrm{PO}_{4}\right)$. This 
is because the diffusion of phenol molecules from the solution to the adsorbent surface is accelerated by increasing the OMW concentration. The increase in uptake capacity of the sorbent with increasing OMW concentration may be due to the increase of sorbate quantity. However, the experimental data were measured at $180 \mathrm{~min}$ to be sure that full equilibrium was attained. The amount of the OMW adsorbed at equilibrium on Olive Stones increased with an increase in the initial OMW concentration of solution to a plateau value which corresponds to the maximum capacity of adsorption. This can be explained by the fact that adsorbent had a limited number of active sites, which would have become saturated above a certain concentration.



Figure 3. kinetics adsorption of $\mathrm{OMW}$ by: a- $\mathrm{KOH}$ and $\mathrm{b}-\mathrm{H}_{3} \mathrm{PO}_{4}$ treated Olive Stones (AOLS) at different $\mathrm{T}^{\circ}$

Despite the fact that the effect of Olive Stones temperature on adsorption is not investigated experimentally in this work, it is worth to mention that several researchers showed that the adsorption of OMW decreases with temperature increase above 20 ${ }^{\circ} \mathrm{C}$ as depicted in Fig.3. Temperature increase reduces the attractive forces between OMW and the adsorbent and increase in adsorbent thermal energy is observed. It also leads to conclusion that physical adsorption has important role besides chemisorption in OMW attachment onto the adsorbent. The equilibrium uptake percentage of OMW ions using Olive Stones was affected by temperature. So, the increase in temperature decreases the physical forces responsible for sorption. Fig.3 shows that the adsorption of OMW by Olive Stones decreased with an increase in temperature from 20 to $47^{\circ} \mathrm{C}$ for the two systems, but we saw that the same capacity of adsorption at 20 and $30{ }^{\circ} \mathrm{C}$ for the system OMWAOLS $(\mathrm{KOH})$ which explain that the treatment of olive stones by $\mathrm{KOH}$ is not better at low temperatures. This behavior indicates that the OMW adsorption is an exothermic process. Furthermore, the decrease uptake of the OMW removal at higher temperatures (above $20^{\circ} \mathrm{C}$ ) may be attributed to the destruction of some polymeric active sites on the adsorbent surface due to bond rupture, as well as the deformation of surfaces at higher temperatures. Consequently, the study found that the OMW adsorption process was affected by temperature and that the optimum working range was $20^{\circ} \mathrm{C}$.

\section{Kinetic Models}

The most famous experimental models obtained in the present work was tested with Pseudo-first, Pseudo-second, intraparticle diffusion, Elovich and Bangham models to predict the adsorption kinetic of OMW on Olive Stones. The adsorption data were analyzed according to the pseudo first-order kinetic model at various effects (agitation. concentration and temperature). The plots of $\ln \left(\mathrm{q}_{\mathrm{e}}-\mathrm{q}_{\mathrm{t}}\right)$ versus t obtained are presented in Table 1 . We can see that the first order kinetic model is not checked for all effects because the curves are not perfectly linear with lower values of $R^{2}$. It is therefore imperative to check the second order model. Table 5 shows the applicability of the pseudo-second-order equation, with a coefficient of correlation $\mathrm{R}^{2}$ greater than 0.99 . Values of the rate constant $\mathrm{k}_{2}$ and equilibrium adsorption capacity $q_{e}$ were calculated from the intercept and slope of the plots of $t / q_{t}$ versus $t$ respectively. Results according to Figures 4,5,6 and 7 show that the adsorption complies with a pseudosecond order equation. Indeed, the $\mathrm{R}^{2}$ in this case is very near to 1 and the calculated qe values $\left(\mathrm{q}_{\mathrm{e}}\right.$ cal $)$, in Table 1 , also agree with the qe experimental $\left(\mathrm{q}_{\mathrm{e}} \exp \right)$. These results indicate that the adsorption system studied belongs to the second-order kinetic model. Several works on OMWW bioadsorption have reported that the pseudo-second order model describes their results. 


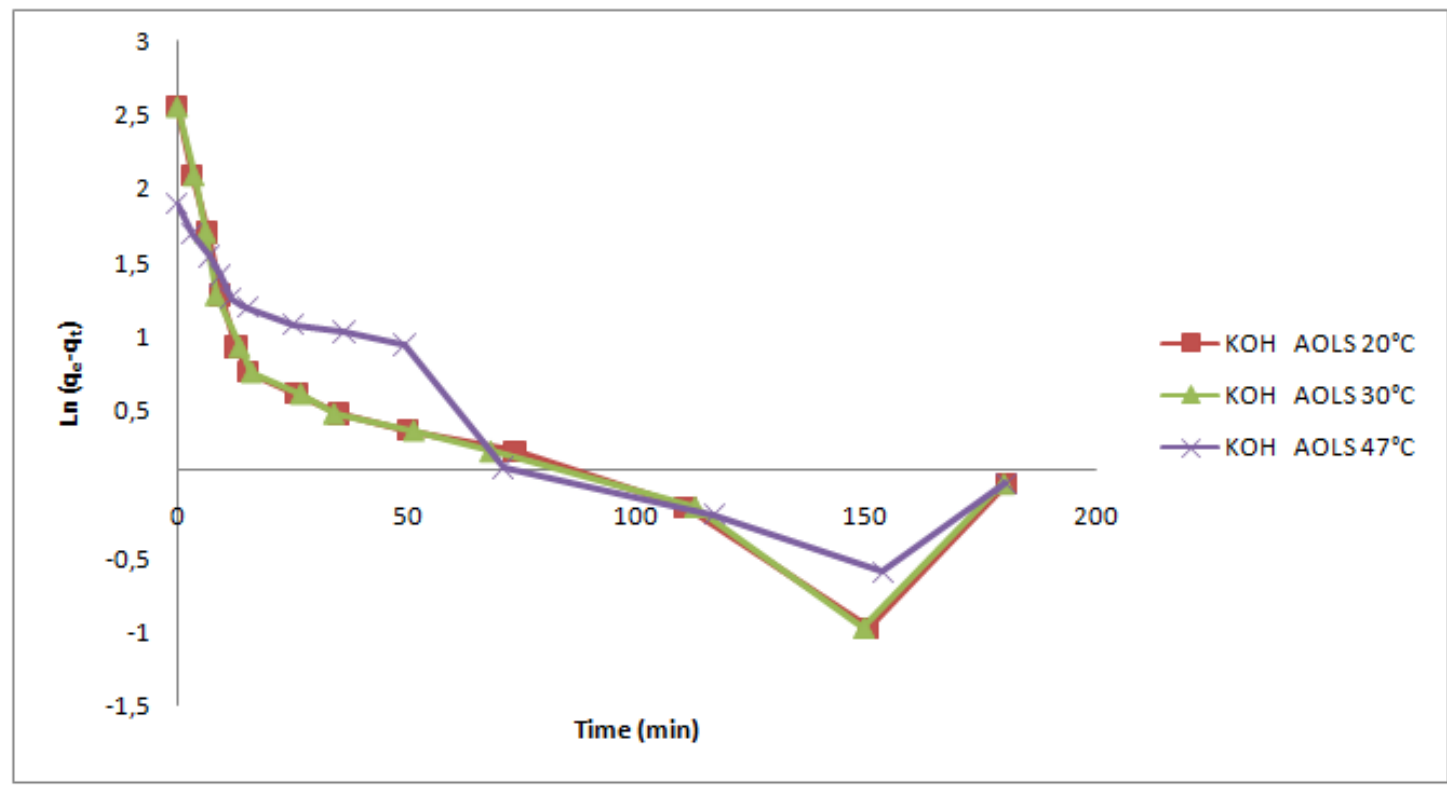

Figure 4. pseudo first order by OMWW onto AOLS by KOH



Figure 5. pseudo first order by OMWW onto AOLS by $\mathrm{H}_{3} \mathrm{PO}_{4}$

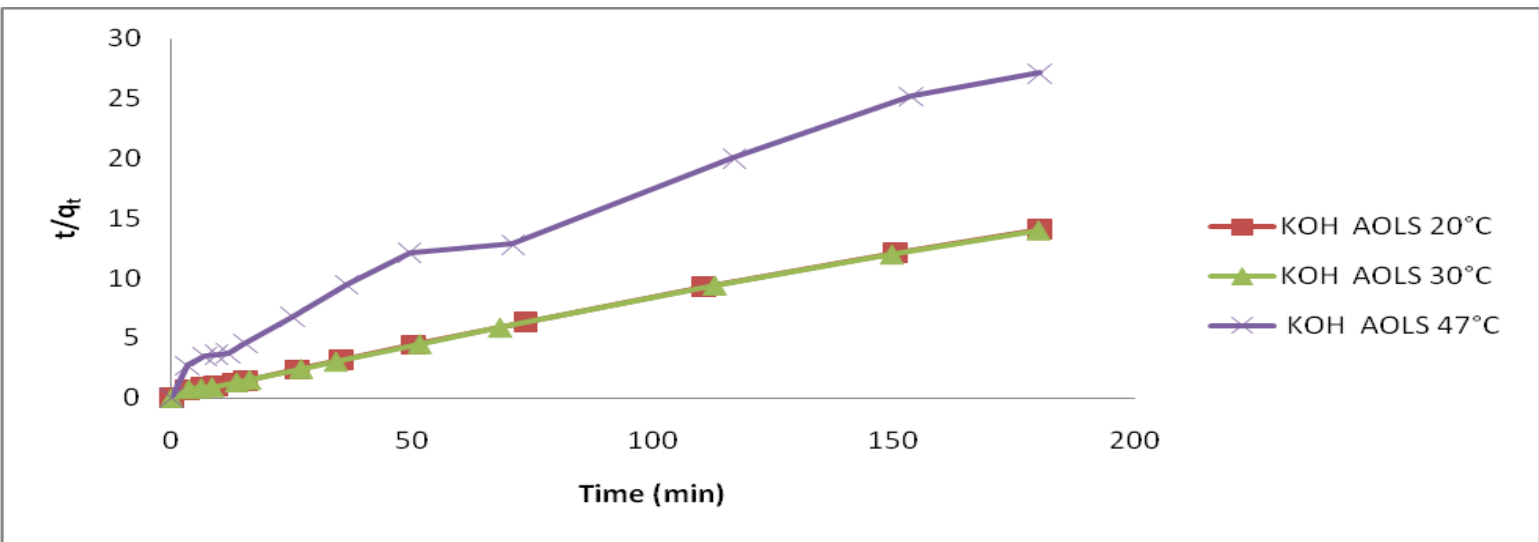

Figure 6. pseudo second order by OMWW onto AOLS by $\mathrm{KOH}$ 


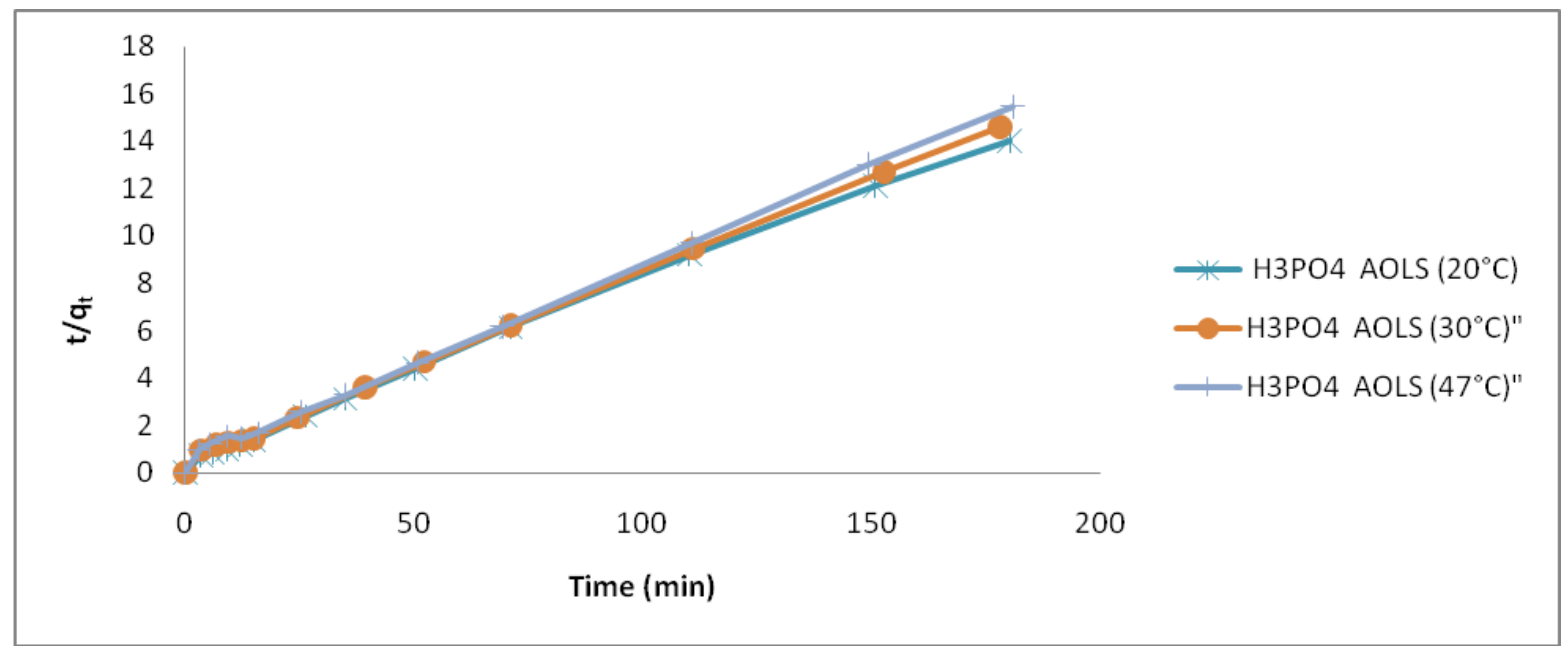

Figure 7. pseudo first order by OMWW onto AOLS by $\mathrm{H}_{3} \mathrm{PO}_{4}$

Table 1. Comparison of the First- and Second-Order Constants Values for adsorption OMW onto KOH and $\mathrm{H}_{3} \mathrm{PO}_{4}$ treated Olive Stones (AOLS) at different temperatures.

\begin{tabular}{|c|c|c|c|c|c|c|c|}
\hline \multirow[t]{2}{*}{ Adsorbent } & & \multicolumn{3}{|c|}{ Pseudo $1^{\text {st }}$ order } & \multicolumn{3}{|c|}{ Pseudo second order } \\
\hline & $\mathbf{T}\left({ }^{\circ} \mathbf{C}\right)$ & $\mathbf{R}_{1}^{2}$ & $\mathrm{k}_{1}(\mathbf{l} / \mathbf{m i n})$ & $\mathrm{qe}_{\mathrm{e}}(\mathrm{mg} / \mathrm{g})$ & $\mathbf{R}_{2}^{2}$ & $\begin{array}{l}\text { k2 } \\
(\mathbf{l} / \mathbf{m i n})\end{array}$ & $\begin{array}{l}\mathrm{qe}_{\mathrm{e}} \\
(\mathrm{mg} / \mathrm{g})\end{array}$ \\
\hline \multirow{3}{*}{$\begin{array}{l}\text { AOLS } \\
\text { (KOH) }\end{array}$} & 20 & 0.64 & 0,0129 & 4,16 & 0.998 & 0,0180 & 12,83 \\
\hline & 30 & 0.64 & 0,0129 & 4,23 & 0.99 & 0,0178 & 12,85 \\
\hline & 47 & 0.84 & 0,0119 & 4,45 & 0.98 & 0,0083 & 6,88 \\
\hline \multirow{3}{*}{$\begin{array}{c}\text { AOLS } \\
\left(\mathbf{H}_{3} \mathbf{P O}_{4}\right)\end{array}$} & 20 & 0.89 & 0,0146 & 7,59 & 0.999 & 0,0039 & 11,53 \\
\hline & 30 & 0.84 & 0,0167 & 4,35 & 0.999 & 0,0202 & 12,46 \\
\hline & 47 & 0.69 & 0,0169 & 4,16 & 0.999 & 0,0285 & 12,03 \\
\hline
\end{tabular}

Table 2. Comparison of Elovich and Bagham models parameters for for adsorption OMW onto $\mathrm{KOH}$ and $\mathrm{H}_{3} \mathrm{PO}_{4}$ treated Olive Stones (AOLS) at different temperatures.

\begin{tabular}{|c|c|c|c|c|c|c|c|}
\hline \multirow[t]{2}{*}{ Adsorbent } & \multirow[t]{2}{*}{$\mathbf{T}\left({ }^{\circ} \mathbf{C}\right)$} & \multicolumn{2}{|c|}{ Elovich } & \multicolumn{4}{|c|}{ Bangham } \\
\hline & & $10^{-2} \beta(\mathrm{g} / \mathrm{mg})$ & $\alpha(\mathrm{mg} / \mathrm{g} \min )$ & $\mathbf{R}^{2}$ & $k_{0}(\mathrm{~mL} / \mathrm{g} / \mathrm{L})$ & $\alpha$ & $\mathbf{R}^{2}$ \\
\hline \multirow{3}{*}{$\begin{array}{l}\text { AOLS } \\
\text { (KOH) }\end{array}$} & 20 & 9,39 & 0.816 & 0,9499 & 5.109 & 0.816 & 0.868 \\
\hline & 30 & 7,60 & 0.680 & 0,9783 & 4.471 & 0.854 & 0.829 \\
\hline & 47 & 8,61 & 0.365 & 0,9336 & 2.974 & 0.402 & 0.952 \\
\hline \multirow{3}{*}{$\begin{array}{c}\text { AOLS } \\
\left(\mathrm{H}_{3} \mathrm{PO}_{4}\right)\end{array}$} & 20 & 9,35 & 0.349 & 0,9971 & 5.450 & 0.025 & 0.932 \\
\hline & 30 & 8,98 & 0.1793 & 0,9934 & 5.500 & 0.05 & 0.944 \\
\hline & 47 & 8,52 & 0.0282 & 0,9939 & 5.387 & 0.034 & 0.986 \\
\hline
\end{tabular}

In the Table 1 presents all of the results concerning the characteristics of the pseudo-firstorder model and the pseudo-second-order kinetic models. This indicates that the OMW-Olive Stones adsorption system obeys the pseudo-second-order kinetic model for the entire sorption period. It was observed that the pseudo-second-order rate constant $\left(\mathrm{k}_{2}\right)$ increased with increasing of temperature from 20 to $47^{\circ} \mathrm{C}$ respectively for the system OMW- AOLS $\left(\mathrm{H}_{3} \mathrm{PO}_{4}\right)$ and this constant decreased for the system OMW- AOLS (KOH). However, the results obtained using the pseudo-second-order model are not enough to predict the diffusion mechanism.

The Elovich parameters $\alpha$ and $\beta$ and Bangham's model constant can be computed from the slope and intercept of the linear plots of $\mathrm{q}_{\mathrm{t}}$ versus $\mathrm{Ln}(\mathrm{t})$, and $\log \left[\mathrm{C}_{0} / \mathrm{C}_{0}-\mathrm{mq}_{\mathrm{t}}\right]$ versus $\log (\mathrm{t})$ respectively for adsorption OMW onto Olive Stones, $\mathrm{KOH}$ and $\mathrm{H}_{3} \mathrm{PO}_{4}$ treated Olive Stones (AOLS) as shown in Table 6. Table 6 lists the kinetic constants $\alpha$ and $\mathrm{k}_{0}$ obtained from the Bangham's equation. Thus, when temperature passed from 20 to $47{ }^{\circ} \mathrm{C}$, for the system 
OMW-AOLS (KOH) the value of $\alpha$ decreased from 0.816 to 0.365 and the value of $\mathrm{k}_{0}$ decreased from 5.109 to $2.886(\mathrm{~mL} / \mathrm{g} / \mathrm{L})$. Hence, or the system OMW-AOLS $\left(\mathrm{H}_{3} \mathrm{PO}_{4}\right)$ the value of $\alpha$ decreased from 0.349 to $0.0282 \mathrm{mg} / \mathrm{g}$ min and the value of $\mathrm{k}_{0}$ decreased from 5.450 to $5.387(\mathrm{~mL} / \mathrm{g} / \mathrm{L})$ when temperature passed from 20 to $47{ }^{\circ} \mathrm{C}$. The experimental data did not give a good correlation. In addition, it was found that the correlation coefficients for the Elovich model are higher than those obtained for Bangham's model (Table 2). This result confirmed that the pore diffusion is not the only rate-controlling step.

The intraparticle diffusion is another kinetic model developed by Weber and Morris that should be used to study the rate-limiting step for OMW adsorption onto olive stone. The intraparticle diffusion is the sole rate-limiting step only if the plots of $\mathrm{q}_{\mathrm{t}}$ versus $\mathrm{t}^{1 / 2}$ pass through the origin, which is not the case in Table 3. The intraparticle diffusion rate constant $\mathrm{K}_{\text {dif }}$ were in the range of $4.312-2.577$ $\mathrm{mg} / \mathrm{g} \cdot \mathrm{min}^{1 / 2}$ and it increases with an increase of temperature for the two system of adsorption of OMW onto KOH and $\mathrm{H}_{3} \mathrm{PO}_{4}$ treated Olive Stones (AOLS). For intraparticle diffusion plots, the first sharper region is the instantaneous adsorption or external surface adsorption that can be attributed to the film diffusion. The second region is the gradual adsorption stage where intraparticle diffusion is the rate limiting. It confirms that intraparticle diffusion was not the only rate limiting mechanism in the sorption process. The values of $\mathrm{k}_{\mathrm{diff} 1}$ and $\mathrm{k}_{\mathrm{diff} 2}$ as obtained from the slopes of the two straight lines are listed in Table 3. The values of the intraparticle diffusion rates $k_{\text {diff1 }}$ are smaller than the film diffusion rates $\mathrm{k}_{\mathrm{diff2}}$. That gives prediction that the dye sorption process may be controlled by the intraparticle diffusion. The constant of Weber and Morris equation depending on the concentration shows that the diffusion constant $(\mathrm{C})$ increases with increasing temperature in a linear fashion. This confirms that the limiting step is the intra-granular distribution.

Table 3. Parameters Obtained from Intraparticle Diffusion Model for adsorption OMW KOH and $\mathrm{H}_{3} \mathrm{PO}_{4}$ treated Olive Stones (AOLS) at different temperatures.

\begin{tabular}{|c|c|c|c|c|c|c|c|}
\hline \multirow[t]{2}{*}{ Adsorbent } & \multirow[t]{2}{*}{$\mathbf{T}\left({ }^{\circ} \mathbf{C}\right)$} & \multicolumn{2}{|c|}{ Intraparticle diffusion } & \multirow[t]{2}{*}{$\mathbf{R}^{2}$} & \multicolumn{2}{|c|}{ Extraparticle diffusion } & \multirow[t]{2}{*}{$\mathbf{R}^{2}$} \\
\hline & & $10^{-3 \cdot} K_{\text {diff } 1}$ & $\mathrm{C}$ & & $\mathrm{K}_{\mathrm{diff2}}$ & $\mathrm{C}$ & \\
\hline \multirow{3}{*}{ AOLS (KOH) } & 20 & 4,49 & 4,0472 & 0,9665 & 4.312 & 136.3 & 0.951 \\
\hline & 30 & 2,03 & 4,125 & 0,9798 & 3.475 & 148.1 & 0.873 \\
\hline & 47 & 6,21 & 2,0717 & 0,992 & 3.191 & 160.1 & 0.869 \\
\hline \multirow{3}{*}{$\operatorname{AOLS}\left(\mathrm{H}_{3} \mathrm{PO}_{4}\right)$} & 20 & 1,56 & 108,31 & 0,9982 & 2.596 & 62.95 & 0.958 \\
\hline & 30 & 1,55 & 112,05 & 0,998 & 2.866 & 82.93 & 0.999 \\
\hline & 47 & 3,28 & 106,03 & 0,9874 & 2.577 & 116.3 & 0.948 \\
\hline
\end{tabular}

\section{Isotherm Modeling of the Sorption Equilibrium Depending on Temperature}

For analyzing experimental data and for describing the equilibrium of biosorption, Langmuir, Freundlich and Temkin isotherms were simulated. Table 4 sHows the fitting parameters for the measured isotherm data for OMW adsorption onto Olive Stones on the linear forms of isotherms. It can be observed that the adsorption isotherm of OMW onto Olive Stones fits Langmuir isotherm well with higher correlation coefficients $\left(\mathrm{R}^{2}\right)$ in comparison with other isotherms, reflecting that the adsorption sites on the surface of Olive Stones are evenly distributed. According to Langmuir adsorption isotherm, the $\mathrm{q}_{\max }$ for OMW are calculated to be $189.83,175.44$ and $172.41 \mathrm{mg} . \mathrm{g}^{-1}$ at 20,30 and 47 ${ }^{\circ} \mathrm{C}$ respectively. The maximum adsorption of OMW on Olive Stones decreases with increasing the temperature, exhibiting the exothermic nature of the adsorption process. The adsorbed amount $\mathrm{q}_{\mathrm{e}}$ of the OMW increases when the concentration of OMW grows then becomes constant which reflects the saturation of the adsorption active sites at various temperatures. Also, the increase in temperature leads to a decrease in the adsorbed amount, it can be said that the low temperatures are of most interest and the maximum monolayer capacity $\mathrm{q}_{\mathrm{m}}$ adsorbed at $20^{\circ} \mathrm{C}$ is $189.83 \mathrm{mg} / \mathrm{g}$ obtained from Langmuir model. In the D-R model, the plot of $\ln \left(\mathrm{q}_{\mathrm{e}}\right)$ versus $\varepsilon^{2}$ gives $\mathrm{K}$ (mol $/(\mathrm{kJ}))$ and the adsorption capacity, Q (mg/g). The constant $\mathrm{K}$ gives the mean free energy of adsorption (E) per molecule of the sorbate when it is transferred to the surface of the solid from infinity in the solution. Calculated D-R constants for the adsorption of OMW on Olive Stones were given in Table 4. The value of regression coefficient of D-R isotherm $R^{2}$ are $0.832,0.871$ and 0.856 is lower than the Langmuir value and the Freundlich value, in this case, D-R equation represents the poorer fit of experimental data than the other isotherm equations. According to the calculated E as 14.821,11.920 and $10.170 \mathrm{~kJ} / \mathrm{mol}$ respectively at $20,20,30$ and $47^{\circ} \mathrm{C}$, which are between 8 and $16 \mathrm{~kJ} / \mathrm{mol}$, the type of adsorption of OMW on the Olive Stones was described as chemical adsorption. 
Table 4. Isotherms constants for OMW adsorption onto Olive Stones AOLS.

\begin{tabular}{|c|c|c|c|}
\hline Models & $\begin{array}{c}\text { T }\left({ }^{\circ} \mathbf{C}\right) \\
\mathbf{2 0}{ }^{\circ} \mathbf{C}\end{array}$ & $30^{\circ} \mathrm{C}$ & $47^{\circ} \mathrm{C}$ \\
\hline \multicolumn{4}{|l|}{ Langmuir } \\
\hline \multirow{3}{*}{$\begin{array}{c}q_{m}(\mathrm{mg} / \mathrm{g}) \\
\mathrm{K}_{1}(\mathrm{l} / \mathbf{m g}) \\
\mathbf{R}^{2}\end{array}$} & 189.83 & 175.44 & 172.41 \\
\hline & 0.0345 & 0.0270 & 0.0259 \\
\hline & 0.995 & 0.991 & 0.999 \\
\hline \multicolumn{4}{|l|}{ Freundlich } \\
\hline \multirow{3}{*}{$\begin{array}{c}\mathbf{K}_{\mathbf{f}} \\
\mathbf{n} \\
\mathbf{R}^{2}\end{array}$} & 51.96 & 31.28 & 26.31 \\
\hline & 4.41 & 3.48 & 3.12 \\
\hline & 0.987 & 0.986 & 0.991 \\
\hline \multicolumn{4}{|l|}{ Temkin } \\
\hline \multirow{3}{*}{$\begin{array}{c}\mathbf{k}_{1} \\
\mathbf{B} \\
\mathbf{R}^{2}\end{array}$} & 0.45 & 0.51 & 0.11 \\
\hline & 38.39 & 31.44 & 47.69 \\
\hline & 0.993 & 0.974 & 0.991 \\
\hline \multicolumn{4}{|l|}{ (D-R) } \\
\hline \multirow{4}{*}{$\begin{array}{c}\text { Qm(mg.g-1) } \\
\text { K(mol2/kJ2) } \\
\text { E(kJ/mol) } \\
\text { R2 }\end{array}$} & 90.74 & 95.23 & 86.73 \\
\hline & 0.012 & 0.013 & 0.014 \\
\hline & 14.821 & 11.920 & 10.170 \\
\hline & 0.832 & 0.871 & 0.856 \\
\hline
\end{tabular}

The separation factor $\mathrm{R}_{\mathrm{L}}$ values for the sorption of OMW on the Olive Stones adsorbent have been shown in Table 5. All $\mathrm{R}_{\mathrm{L}}$ values fall between zero and one; this fact supports the previous observation where the Langmuir isotherm was favorable for OMW sorption for all studied temperatures.

Table 5. Dimensionless Separation Factor $\left(\mathrm{R}_{\mathrm{L}}\right)$ at Different Initial OMW Concentrations Studied at Different Solution Temperatures for the Sorption of OMW onto the Olive Stones Adsorbent

\begin{tabular}{|c|c|c|c|}
\hline \multirow{2}{*}{$\mathbf{C}(\mathbf{m g} / \mathbf{g})$} & \multicolumn{2}{|c|}{$\mathbf{T}\left({ }^{\circ} \mathbf{C}\right)$} & $\mathbf{4 7}$ \\
\cline { 2 - 4 } $\mathbf{K}_{\mathbf{1}}(\mathbf{l} / \mathbf{m g})$ & $\mathbf{2 0}$ & $\mathbf{3 0}$ & 0.0259 \\
\hline $\mathbf{2 0}$ & 0.0345 & 0.0270 & 0.6648 \\
$\mathbf{4 0}$ & 0.33014 & 0.6268 & 0.4979 \\
\hline $\mathbf{6 0}$ & 0.1977 & 0.4565 & 0.3979 \\
\hline $\mathbf{n}$ & 0.1411 & 0.3589 & 3.12 \\
\hline $\mathbf{1}$ & 4.41 & 3.48 & 0.179 \\
\hline
\end{tabular}

Freundlich constants can be determined from the plot of $\ln \left(\mathrm{q}_{\mathrm{e}}\right)$ versus $\ln \left(\mathrm{C}_{\mathrm{e}}\right)$. Thus we can generate the value of $\mathrm{K}_{\mathrm{F}}$ from the intercept and $1 / \mathrm{n}$ from the slope and coefficients of determination are presented in Table 2. Freundlich model is not comparable to that obtained from Langmuir model linear form. This result indicates that the experimental data were not fitted well Freundlich model (low correlation coefficient). The values of $\mathrm{n}_{\mathrm{f}}$ are higher than unity, indicating that adsorption of OMW onto OLS is a favorable physical process (obtained in Table 4). The Temkin constants $\mathrm{k}_{1}$ and $\mathrm{B}_{1}$ are calculated from the slope and the intercept of $\mathrm{q}_{\mathrm{e}}$ versus $\ln \mathrm{C}_{\mathrm{e}}$. The linear isotherm constants and coefficients of determination are presented in Table 4. Examination of the data shows that the Temkin isotherm is not applicable to the OMW adsorption onto Olive Stones judged by low correlation coefficient $\left(\mathrm{R}^{2}\right)$.

\section{Thermodynamic Parameters of Adsorption}

Thermodynamics experiments were carried out at a temperature range of $20-47^{\circ} \mathrm{C}$. Fig. 8 shows the plot of $\ln \mathrm{K}_{\mathrm{L}}$ versus $1 / \mathrm{T}$ and the values of estimated thermodynamic parameters are given in Table 6 . 


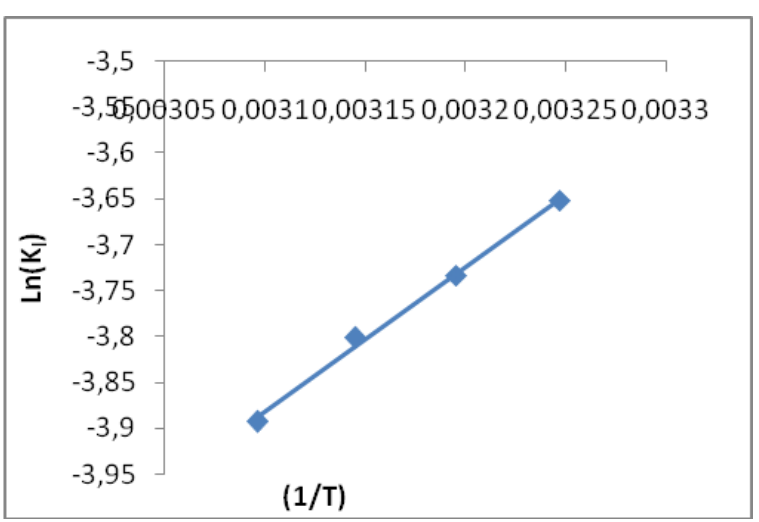

Figure 8. Plot of the adsorption of OMW

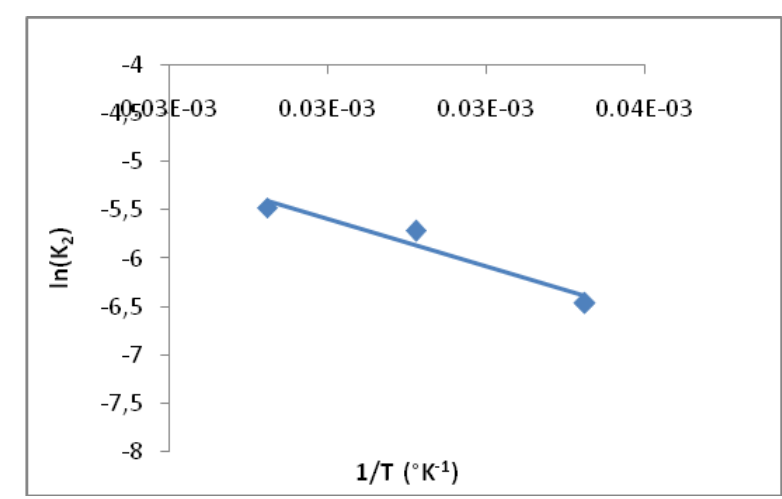

Figure 9. Arrhenius plots for the adsorption of OMW onto Olive Stones at various temperatures.

As can be observed, the negative value of $\Delta \mathrm{H}^{\circ}(-105.54 \mathrm{~kJ} / \mathrm{mol})$ shows that the adsorption is exothermic as process. The negative value of $\Delta \mathrm{S}^{\circ}\left(-72.91 \mathrm{~J} / \mathrm{mol} .{ }^{\circ} \mathrm{K}\right)$ can be used to describe the randomness at the solid/solution interface during the adsorption process. The Gibbs energy $\left(\Delta G^{\circ}\right)$ increased from $8.38 \mathrm{~kJ} / \mathrm{mol}$ to $9.35 \mathrm{~kJ} / \mathrm{mol}$ with an increase in temperature from 20 to $47{ }^{\circ} \mathrm{C}$ indicate a decrease in feasibility of adsorption at higher temperatures and the spontaneous nature of the adsorption.

Table 6. Thermodynamic Parameters Obtained from Isotherm Adsorption of OMW onto Olive Stones.

\begin{tabular}{|c|c|c|c|c|c|c|c|}
\hline $\mathbf{T}\left({ }^{\circ} \mathbf{C}\right)$ & $\mathbf{K}_{\mathbf{L}}(\mathbf{L} / \mathbf{m g})$ & $\mathbf{T}\left({ }^{\circ} \mathbf{K}\right)$ & $\mathbf{1 0}^{\mathbf{3}} / \mathbf{T}\left({ }^{\circ} \mathbf{K}^{\mathbf{- 1}}\right)$ & $\mathbf{L n}(\mathbf{K})$ & $\boldsymbol{\Delta G}(\mathbf{K J} / \mathbf{m o l})$ & $\boldsymbol{\Delta} \mathbf{H}(\mathbf{K J} / \mathbf{m o l})$ & $\boldsymbol{\Delta S}\left(\mathbf{J} / \mathbf{m o l}^{* \circ} \mathbf{K}\right)$ \\
\hline $\mathbf{2 0}$ & 0.0345 & 298 & 3.36 & -3.38 & 8.38 & -105.54 & -72.91 \\
\hline $\mathbf{3 0}$ & 0.0270 & 303 & 3.30 & -3.61 & 6.10 & & \\
\hline $\mathbf{4 7}$ & 0.0259 & 308 & 3.25 & -3.65 & 9.35 & \\
\hline
\end{tabular}

Concerning the evaluation of the activation energy $\left(\mathrm{E}_{\mathrm{a}}\right)$ of the adsorption, the Fig.9 shows a linear relationship between the logarithm of rate constant and the inverse temperature and gives an estimation value $\mathrm{E}_{\mathrm{a}}=-20.5879582 \mathrm{~kJ} / \mathrm{mol}$ and $\mathrm{k}_{0}=10,327$ (g/mg.min). The negative values of $\mathrm{E}_{\mathrm{a}}$ indicate the presence of an energy barrier in the adsorption and confirming the nature of physisorption processes of OMW on the surface of Olive Stones.

\section{Conclusion}

The batch adsorption experiments proved that $\mathrm{H}_{3} \mathrm{PO}_{4}$ Treated Olive Stones (TOLS) is a promising abundant, low cost and high capacity adsorbent for the removal of Olive Mill Wastewater (OMW). High adsorption capacity of total Olive Mill Wastewater onto $\mathrm{H}_{3} \mathrm{PO}_{4}$ Treated Olive Stones is observed The adsorption capacity is exponentially increased with initial OMW concentration. The equilibrium time is independent of the concentration and the amount adsorbed at equilibrium increases with concentration. This is because the diffusion of OMW molecules from the solution to the surface of the adsorbent is accelerated by increasing the dye concentration. This work confirms that the Olive Stones could be used for the removal of OMW from aqueous solutions. The adsorbed amount decreases with increasing temperature. Equilibrium studies signify favorable adsorption isotherm for OMW adsorption onto Olive Stones. Langmuir isotherm better represents the equilibrium system than Freundlich and Temkin isotherm. Results indicate that the adsorption isotherm data were fitted good agreement with the Langmuir isotherm model by comparing the values of the linear correlation coefficient $R^{2}$. The adsorption process is considered to be of medium speed at low agitation speed; Equilibrium is almost achieved after $7 \mathrm{hrs}$ of OMW contact with Treated Olive Stones. Kinetic modeling indicates that total OMW adsorption is best represented by pseudosecond order rate. The adsorption process followed pseudo-second order kinetics and was spontaneous and exothermic. This study shows that Olive Stones is an effective adsorbent for removal of OMW from aqueous solutions.

\section{References}

1- D. Simeonov, L. Spasov, P. Simeonova, Statistical calibration of model solution of analytes. Ecol. Chem. Eng. S., 2012, 19, 67-75.

2- A. Mittal, L. Kurup, V.K. Gupta, Use of waste materials-bottom ash and de-oiled soya, as potential adsorbents for the removal of amaranth from aqueous solutions. J. Hazard. Mater. 2005, $117,171-178$.

3- A.Y. Dursun, O. Tepe, Internal mass transfer effect on biodegradation of phenol by $\mathrm{Ca}$ - 
alginate immobilized Ralstonia eutropha. J. Hard. Mater. 2005, 126, 105-111.

4- A. Dąbrowski, P. Podkościelny, Z. Hubicki, M. Barczak, Adsorption of phenolic compounds by activated carbon - a critical review. Chemosphere. 2005,58, 1049-1070.

5- B. Taraba, Adsorption heats of phenol on activated carbon using adapted method of immersion calorimetry. Journal of thermal analysis and calorimetry, 2011,107, 923-926.

6- S. Wang, H. Niu, T. Zeng, X. Ma, Y. Cai, $X$. Zhao, Fabrication of magnetic mesoporous carbon and its application for adsorptive removal of 2, 4, 6-trichlorophenol (TCP) from aqueous solution. Cryst. Eng. Comm. 2014, 25, 5598-5607.

7- A. Dąbrowski, P. Podkościelny, Z. Hubicki, M. Barczak, Adsorption of phenolic compounds by activated carbon-a critical review. Chemosphere, 2005, 58,1049-1070.

8- Y. Wang, J. Niu, Y. Li, T. Zheng, Y. Xu, Y. Liu, Performance and mechanisms for removal of perfluorooctanoate (PFOA) from aqueous solution by activated carbon fiber. RSC Advances, 2015, 106, 86927-86933.

9- L. A. Rodrigues, T.M.B. Campos, M.O. Alvarez-Mendes, A. dos Reis Coutinho, K.K. Sakane, G.P. Thim, Phenol removal from aqueous solution by carbon xerogel. Journal of sol-gel science and technology, 2012, 63, 202-210.

10- S. Yao, H. Lai, Z. Shi, Biosorption of methyl blue onto tartaric acid modified wheat bran from aqueous solution. Iranian journal of environmental health science \& engineering, 2012, 9,16.

11- M., Seredych, T.J. Bandosz, Removal of cationic and ionic dyes on industrial- municipal sludge based composite adsorbents. Industrial \& engineering chemistry research, 2007, 46, 1786-1793.

12- M. Ahmaruzzaman, S.L. Gayatri, Activated tea waste as a potential low-cost adsorbent for the removal of p-nitrophenol from wastewater. Journal of Chemical \& Engineering Data, 2010, 5511, 4614-4623.

13- H. Mine Kurtbay, Z. Bekçi, M. Merdivan, K. Yurdakoç, Reduction of ochratoxin A levels in red wine by bentonite, modified bentonites, and chitosan. Journal of agricultural and food chemistry, 2008, 56, 2541-2545.

14- C. Namasivayam, S. Sumithra, Adsorptive removal of catechol on waste $\mathrm{Fe}$ (III)/Cr (III) hydroxide: equilibrium and kinetics study. Industrial \& engineering chemistry research, 2004, 43, 7581-7587.

15- O. Zahraa, L. Sauvanaud, G. Hamard, M. Bouchy, Kinetics of atrazine degradation by photocatalytic process in aqueous solution. International Journal of Photoenergy, 2003, 5, 87-93.
16- Lin SH, Juang RS. Adsorption of phenol and its derivatives from water using synthetic resins and low-cost natural adsorbents: a review. J. Envion. Manage. 2009, 90, 1336-1349.

17- G. Dursun, H. Cicek, A.Y. Dursun, Adsorption of phenol from aqueous solution by using carbonised beet pulp. Journal of hazardous materials, 2005, 125, 175-182.

18- B. Özkaya, Adsorption and desorption of phenol on activated carbon and a comparison of isotherm models. Journal of hazardous materials, 2006,129, 158-163.

19- P.A. Mangrulkar, S.P. Kamble, J. Meshram, S.S. Rayalu, Adsorption of phenol and ochlorophenol by mesoporous MCM-41. Journal of Hazardous Materials, 2008, 160, 414-421.

20- X. Jin, M.Q. Jiang, X.Q. Shan, Z.G. Pei, Z. Chen, Adsorption of methylene blue and orange II onto unmodified and surfactantmodified zeolite. J. Colloid Interface Sci. 2008, 328, 243-247.

21- M. Iqbal, M.Z. Ahmad, I.A. Bhatti, K. Qureshi, A. Khan, Cytotoxicity reduction of wastewater treated by advanced oxidation process. Chemistry International, 2015,1, 53-59.

22- B. Dass, P. Jha, Batch adsorption of phenol by improved activated Acacia nilotica branches char: equilibrium, kinetic and thermodynamic studies. Int J Chem Tech Res, 2015, 8, 269-279.

23- M. Niaounakis, C.P. Halvadakis, Olive processing waste management: literature review and patent survey, Elsevier, 2006, 5.

24- A. Nait-Merzoug, A. Benjaballah, O. Guellati, Préparation et caractérisation d'un charbon actif à base d'un déchet agricole, 2016.

25- N. F. Cardoso, R.B. Pinto, E.C. Lima, T. Calvete, C.V. Amavisca, B. Royer, I.S. Pinto, Removal of remazol black B textile dye from aqueous solution by adsorption. Desalination, 2011, 269, 92-103.

26- D.J. Cao, X. Yang, G. Geng, X.C. Wan, R.X. Ma, Q. Zhang, Y.G. Liang, Absorption and subcellular distribution of cadmium in tea plant (Camellia sinensis cv.

"Shuchazao"). Environmental Science and Pollution Research, 2018, 25, 15357-15367.

27- L.B. Lim, N. Priyantha, D.T.B. Tennakoon, H.I. Chieng, M.K. Dahri, M. Suklueng, Breadnut peel as a highly effective low-cost biosorbent for methylene blue: equilibrium, thermodynamic and kinetic studies. Arab J Chem. 2017, doi: 10. S3216-S3228.

28- E. Ayranci, O. Duman, Adsorption behaviors of some phenolic compounds onto high specific area activated carbon cloth. Journal of hazardous materials, 2005, 124, 125-132.

29- O. Moradi, M. Yari, P. Moaveni, M. Norouzi, Removal of p-nitrophenol and naphthalene from petrochemical wastewater using SWCNTs and SWCNT-COOH surfaces. Fullerenes, Nanotubes and Carbon Nanostructures, 2012, 20, 85-98. 
30- L. Seid, D. Chouder, N. Maouche, I. Bakas, N. Barka, Removal of Cd (II) and Co (II) ions from aqueous solutions by polypyrrole particles: Kinetics, equilibrium and thermodynamics. J. Taiwan Inst. Chem. Eng. 2014, 45, 2969-2974.

31- M. Arami, N.Y. Limaee, N.M. Mahmoodi, Evaluation of the adsorption kinetics and equilibrium for the potential removal of acid dyes using a biosorbent. Chem. Eng. J. 2008, 139, 2-10.

32- R.J. Umpleby II, S.C. Baxter, M. Bode, J.K. Berch Jr, R.N. Shah, K.D. Shimizu, Application of the Freundlich adsorption isotherm in the characterization of molecularly imprinted polymers. Analytica Chimica Acta, 2001, 435, 35-42.

33- N. Barka, A. Assabbane, A. Nounah, L. Laanab, Y.A. Ichou, Removal of textile dyes from aqueous solutions by natural phosphate as a new adsorbent. Desalin. 2009, 235, 264-275.

34- A. Gürses, A. Hassani, M. Kıranşan, Ö. Açışl1, S. Karaca, Removal of methylene blue from aqueous solution using by untreated lignite as potential low-cost adsorbent: kinetic, thermodynamic and equilibrium approach. J. Water Process Eng. 2014, 2, 10-21.

35- S. Arellano-Cárdenas, T. Gallardo-Velázquez, G. Osorio-Revilla, M. López-Cortéz, B. Gómez-Perea, Adsorption of phenol and dichlorophenols from aqueous solutions by porous clay heterostructure (PCH). J. Mex. Chem. Soc. 2005, 49, 287-291.

36- J.P. Silva, S. Sousa, J. Rodrigues, H. Antunes, J.J. Porter, I. Gonçalves, S. Ferreira-Dias, Adsorption of acid orange 7 dye in aqueous solutions by spent brewery grains. Sep. Purif. Technol. 2004, 40, 309-315.

37- A. Alatrache, A. Cortyl, P. Arnoux, M.N. Pons, O. Zahraa, Sulfamethoxazole removal from polluted water by immobilized photocatalysis. Toxicological \& Environmental Chemistry, 2015, 97, 32-42.
38- S.A. Mohtashami, N.A. Kolur, T. Kaghazchi, R. Asadi-Kesheh, M. Soleimani, Optimization of sugarcane bagasse activation to achieve adsorbent with high affinity towards phenol. Turkish Journal of Chemistry, 2018, 42, 1720-1735

39- M. Ahmaruzzaman, S.L. Gayatri, Activated neem leaf: a novel adsorbent for the removal of phenol, 4-nitrophenol, and 4-chlorophenol from aqueous solutions. Journal of Chemical \& Engineering Data, 2011,56, 3004-3016.

40- O. Tepe, A.Y. Dursun, Combined effects of external mass transfer and biodegradation rates on removal of phenol by immobilized Ralstonia eutropha in a packed bed reactor. Journal of hazardous materials, 2008,151, 9-16.

41- P.D. Pathak, S.A. Mandavgane, B.D. Kulkarni, Fruit peel waste as a novel low-cost bio adsorbent. Reviews in Chemical Engineering, 2015, 31, 361-381.

42- W. Wei, Q. Wang, A. Li, J. Yang, F. Ma, S. Pi, $\mathrm{D}$. $\mathrm{Wu}$, Biosorption of $\mathrm{Pb}$ (II) from aqueous solution by extracellular polymeric substances extracted from Klebsiella sp. J1: Adsorption behavior and mechanism assessment. Scientific reports, 2016, 6, 31575 .

43- A.T.M. Din, B.H. Hameed, A.L. Ahmad, Batch adsorption of phenol onto physiochemicalactivated coconut shell. J. Hazard. Mater.2009,161,1522-1529.

44- A.H. Mahvi, A. Maleki, A. Eslami, Potential of rice husk and rice husk ash for phenol removal in aqueous systems. American Journal of Applied Sciences. 2004, 321-326.

45- J. A. Hefne, W.K. Mekhemer, N.M. Al, O.A. Aldayel, T. Alajyan, Kinetic and thermodynamic study of the adsorption of $\mathrm{Pb}$ (II) from aqueous solution to the natural and treated bentonite. International Journal of Physical Sciences, 2008, 3, 281-288. 